\title{
Faculty Perspectives on Doctoral Student Socialization in Five Disciplines
}

\author{
Susan K. Gardner \\ The University of Maine, Orono, ME, USA
}

\author{
susan.k.gardner@maine.edu
}

\begin{abstract}
Socialization has become a common framework through which to view the doctoral student experience. A growing body of literature has examined the student perspective of this socialization experience but the perspective of the faculty member has been relatively absent in these discussions, despite the vital role they play in the process. Sixteen doctoral faculty members in the disciplines of engineering, oceanography, psychology, history, and a self-designed interdisciplinary program at one institution were interviewed to determine their perspectives on the doctoral student socialization process and their role in it. Using Bragg's (1976) and Weidman, Twale, and Stein's (2001) framework of socialization to analyze these interviews, findings emerged regarding faculty perspectives often on programmatic and structural components but rarely on the role of peers or their own informal role in the socialization process. Implications for policy, practice, and future research are included.
\end{abstract}

Keywords: socialization, doctoral, faculty, advisors

\section{Introduction}

Socialization has become the prevailing framework through which the doctoral student experience has been examined (Austin, 2002; Baird, 1992; Bess, 1978; Clark \& Corcoran, 1986; Ellis, 2001; Gardner, 2007; Keith \& Moore, 1995; Mendoza, 2007; Turner \& Thompson, 1993). Socialization in graduate school is thought to occur as a result of experiences both inside and outside of the classroom (Weidman, Twale, \& Stein, 2001) but it is the doctoral student's interactions with faculty members that have received the most attention in the existing literature. In particular, faculty members play myriad roles in the socialization of doctoral students, including instructors in the classroom, supervisors for students with assistantships, committee members for the thesis or dissertation, advisor or chair of the research process, and even mentor (Isaac, Quinlan, \& Walker, 1992; Pease, 1967; Weidman \& Stein, 2003). In this way, faculty members serve as gatekeepers into and out of doctoral programs (Weidman et al., 2001). And, while multiple studies exist that examine how doctoral students view their socialization experiences in graduate school (e.g., Gardner, 2007; Gonzalez, 2006; Mendoza, 2007; Turner \& Thompson, 1993) corresponding

Material published as part of this publication, either on-line or in print, is copyrighted by the Informing Science Institute. Permission to make digital or paper copy of part or all of these works for personal or classroom use is granted without fee provided that the copies are not made or distributed for profit or commercial advantage AND that copies 1) bear this notice in full and 2) give the full citation on the first page. It is permissible to abstract these works so long as credit is given. To copy in all other cases or to republish or to post on a server or to redistribute to lists requires specific permission and payment of a fee. Contact Publisher@InformingScience.org to request redistribution permission. studies examining the faculty member's perspective in this socialization process are relatively absent. Such an examination is warranted given the primary role that faculty play in the socialization process of doctoral students (Weidman et al., 2001). The purpose of this study was to better understand faculty members' perceptions about the socialization process and their role in it within five 
doctoral programs. The paper begins with an overview of the literature related to doctoral student socialization and the faculty role in doctoral education. The methods used to conduct the study, the findings, and the discussion then follow, concluding with implications for policy, practice, and future research.

\section{Doctoral Student Socialization}

Socialization is the process through which an individual learns to adopt the values, skills, attitudes, norms, and knowledge needed for membership in a given society, group, or organization (Austin, 2002; Bragg, 1976; Merton, 1957; Tierney, 1997; Van Maanen, 1984; Weidman et al., 2001). In relation to the graduate student, socialization is imperative to a successful graduate school experience (Clark \& Corcoran, 1986) as unsuccessful socialization contributes to the decision to depart from the degree program (Council of Graduate Schools, 2004). Unlike other models of professional socialization, however, graduate student socialization is unique in that the student is becoming socialized not only to the graduate school environment but simultaneously to the professional role (Austin, 2002; Golde, 1998; Rosen \& Bates, 1967). The socialization that occurs is also specific to the discipline in which the student is located (Golde, 2005).

The avenues through which socialization occurs are tri-fold, according to Bragg (1976): (a) the interaction of students with the structures of the educational setting, (b) the interaction among students in the same educational program (i.e., discipline or department), and (c) the interaction between students and faculty members (p. 14). The structure of the educational setting "[a]ffect[s] or facilitate[s] change in the student's attitudes and values because they reflect the attitudes and values of the profession itself" (p. 14). These structural elements include the student selection process, the isolation of students from outside influences, the consistency of program goals, the explicitness of values and role models, the provision of opportunities for practicing responses (i.e., coursework, examinations, internships, or practica), and the provision of both positive and negative sanctions as feedback to students. Interactions with peers also serve to promote the socialization process, particularly as newer students interact with more veteran students in "learning the ropes" of the program. At the same time, students bond with one another as they simultaneously experience the different trials and tribulations of graduate school (Gardner, 2007). The last element described by Bragg - the interaction between students and faculty members - is the focus of this paper. Together, these three elements create the conditions and context for the socialization of doctoral students in academic programs.

\section{The Faculty Role in Doctoral Student Socialization}

The role of faculty members is central to the student socialization process (Baird, 1995; Bragg, 1976; Clark \& Corcoran, 1986; Rosen \& Bates, 1967). Bragg commented, "While the catalog informs the student of a program's structure by outlining its goals and its dominant values, the faculty members are the primary socializing agents." She continued, "The faculty members transmit their attitudes, values, and behavioral norms both formally - through the structures they establish and through the courses they teach - and informally - through individual advising and supervising of study and through social activities" (pp. 19-20). Bragg posited that through role modeling behaviors as well as through formal and informal feedback, the socialization process occurs.

According to Weidman et al. (2001), graduate student socialization is specifically mechanized through three core elements, including (a) knowledge acquisition, or the knowledge and skills needed for the profession; (b) investment, or a commitment of time, energy, or status to the profession; and (c) involvement, including interaction with more advanced professionals. The role of the faculty member is both implicit and explicit in these three elements. For example, Weidman et al. pointed out that it is the "faculty who establish the norms for teaching, research, and service, 
[who] shape the curriculum as well as the organization of instruction and social relationships among the members of the academic program, [and] admit students and decide on the kinds of financial support to be offered" (p. 38). Even in the second core element of investment, the faculty role is implied as students interact with their faculty, and "learn the ropes" through observation of their faculty members (p. 63). In one of the few empirical studies examining the view of doctoral faculty related to their advising practices, Barnes and Austin (2009) found that the exemplary advisors they interviewed felt their roles to include helping their students be successful, such as through assessing their students' needs, helping them progress, and helping them deal with failure, a finding echoed by Samuel and Kohun (2010). In addition, the faculty felt their roles were to assist students to develop as researchers and professionals through helping their students become independent in their research projects and assisting them in networking efforts.

Faculty members consequently exert an enormous influence upon their students and may often serve in "gate-keeping" roles (Weidman et al., 2001, p. 66). Indeed, much of the literature that connects the faculty member to the doctoral student is riddled with commentary about the power differential that marks this relationship (Aguinis, Nesler, Quigley, Suk-Jae, \& Tedeschi, 1996; Bargar \& Mayo-Chamberlain, 1983; Clark \& Corcoran, 1986; Heinrich, 1995; Schroeder \& Mynatt, 1993; Sorenson \& Kagan, 1967; Zhao, Golde, \& McCormick, 2007). As such, scholars such as Tierney (1997) and Antony (2002) have criticized prevailing views of the socialization process, pointing to the unidirectional conceptualization of the experience as one that does not allow for the socialized to also affect the socializing agent or the socializing organization. Indeed, recent research on underrepresented doctoral student populations has demonstrated the role students can play in challenging the socialization process (e.g., Gonzalez, 2006).

Taken together, the existing research has tended to focus upon how students view their socialization (Austin, 2002; Frentz, 1991; Gardner, 2007; Gonzalez, 2006; Holley, 2006; Margolis \& Romero, 1998; Mendoza, 2007; Turner \& Thompson, 1993), rather than focusing on the advisors' and faculty members' perspectives of their own role in the socialization process. Given the key role that faculty play in the socialization process (Baird, 1995; Weidman et al., 2001), an understanding of their roles, as they see them, will greatly assist in providing more successful socialization experiences for doctoral students.

\section{Methods}

In order to address this gap in the existing literature on doctoral student socialization, the current study asked doctoral faculty in history, psychology, engineering, oceanography, and an interdisciplinary program at one research institution to describe their role in the socialization process. Qualitative research methods were chosen for this study as they are best suited for understanding participants' perspectives of "the meaning of the events, situations, and actions they are involved with and of the accounts that they give of their lives and experiences" (Maxwell, 1996, p. 17). As the doctoral student socialization process differs by discipline (Golde, 2005), as does the faculty conceptualization of that experience (Gardner, 2009), these diverse disciplinary (Biglan, 1973) and programmatic areas were included in the study. In addition to programmatic and disciplinary diversity, these five programs were also chosen for their representation among the highest doctoral completion rates at the institution examined (see Table 1). Given the connections between a successful socialization experience and doctoral student success (Clark \& Corcoran, 1986), this purposeful sampling method was utilized to allow for the inclusion of faculty members who had extensive experience working with doctoral students as well as those who had been successful in socializing students within one institutional context. Specifically, these faculty were credited with graduating high numbers of doctoral students, thereby contributing to high completion rates. The focus on the singular institutional context, hereafter referred to as Land Grant University (LGU), was also purposeful in that an institution's culture also plays a key role in the student experience 
(Kuh \& Whitt, 1988). An institution's culture ultimately influences behaviors through its transmission of values and goals, which is "important for understanding what the institution stands for and how and why its members behave in different ways" (Bess \& Dee, 2008, p. 362).

LGU is a research university classified with high research activity (The Carnegie Foundation, 2010) located on the East Coast of the United States. With an undergraduate student population of nearly 9,000 and a graduate student population of almost 2,400, it is relatively small in relation to other land grant institutions while also being geographically isolated. LGU is one of a number of contemporary institutions interested in gaining more prestige through its rankings and relatively new emphasis on research (Aldersley, 1995), which has also manifested itself through an increased focus on doctoral education. From a previous study, LGU's mean completion rate across its 40 doctoral programs was calculated at $54.6 \%$, which is slightly below the national average of $57 \%$ (Council of Graduate Schools, 2008).

Inclusion of doctoral programs in the current study resulted in the top five programs in relation to their completion rate, ranging from $58.6 \%$ in history to $71.1 \%$ in engineering (see Table 1 ). Department chairs and graduate coordinators were contacted in each of the five programs and asked to identify faculty members with extensive experience teaching, advising, and chairing doctoral students. These 16 individuals were then contacted via email for their participation in the study, with all contacted faculty members agreeing to be interviewed. While a relatively small number of faculty members were interviewed in each department, they nevertheless represented the faculty in these departments with the most experience in advising doctoral students.

\begin{tabular}{|l|l|l|l|}
\hline \multicolumn{4}{|c|}{ Table 1: Characteristics of faculty participants } \\
\hline \multicolumn{1}{|c|}{$\begin{array}{c}\text { DISCIPLINE / } \\
\text { PROGRAM }\end{array}$} & $\begin{array}{c}\text { TOTAL FACULTY } \\
\text { INTERVIEWED }\end{array}$ & $\begin{array}{c}\text { PROGRAM } \\
\text { COMPLETION } \\
\text { RATE }\end{array}$ & $\begin{array}{c}\text { MEAN YEARS AT } \\
\text { INSTITUTION }\end{array}$ \\
\hline History & 3 & $58.6 \%$ & 18 \\
\hline Psychology & 2 & $60.6 \%$ & 16 \\
\hline Interdisciplinary & 4 & $62.0 \%$ & 14 \\
\hline Oceanography & 3 & $62.9 \%$ & 17.67 \\
\hline Engineering & 4 & $71.1 \%$ & 9.75 \\
\hline
\end{tabular}

Interviews with the 16 faculty members were conducted in the winter and spring of 2009. After providing informed consent, face-to-face interviews were conducted utilizing a loosely-structured protocol, which allowed participants to diverge from the main topics and to further explore concepts and ideas. Questions focused around how faculty interacted with students in regard to their teaching and advising practices, how faculty perceived successful students, and how they and the department or program facilitated this success. Finally, faculty were pointedly asked about how they actually go about socializing students. Interviews lasted for approximately 45 to 90 minutes and were audio-taped and later transcribed verbatim.

Analysis of the data was conducted through the use of open-coding in relation to the three socialization elements of Bragg (1976). Trustworthiness of the data collected and subsequent analysis was obtained through peer debriefing (Maxwell, 1996), wherein another colleague was given access to transcripts for their analysis and verification of themes related to Bragg; member checking, wherein faculty were asked to review the themes that emerged from their interviews; as well 
as through triangulation of data sources (Bogdan \& Biklen, 2003; Maxwell, 1996) as the current study was a part of a larger study in which students and administrators were interviewed at LGU.

\section{Findings}

From the interviews with the 16 faculty members at LGU, findings emerged related to their views of their role in the doctoral student socialization process. These findings are presented in relation to the three socialization elements provided by Bragg (1976), including (a) the interaction of students with the structure of the academic setting, (b) the interaction among students in the program, and (c) the interaction between students and faculty members. The findings then conclude with an overview of the faculty members' explicit descriptions of their role in the socialization process.

\section{Interaction of Students with the Structure of the Academic Setting}

Bragg (1976), citing LeVine (1966), outlined the six structural features of educational institutions that define the boundaries in which the student interacts, thereby effecting change in the student's attitudes and values (p. 14). These features include (a) the student selection process, (b) the isolation of students from outside influences, (c) the consistency of program goals, (d) the explicitness of values and role models, (e) the provision of opportunities for practicing responses (i.e., coursework, examinations, internships, or practica), and (f) the provision of both positive and negative sanctions as feedback to students. Within the current study, each of the faculty described these core features to a greater or lesser extent.

Psychology 1 "We give about three to five offers out of over a hundred applications each year. Even by LGU standards they're really stellar when they come in so [attrition] is not really an issue."

Engineering 1 "I don't think we have any secret magical things here. I think since we get a lot of applications for our program we can be selective. Not to say that every student we get is outstanding or never in trouble but on average there are good students who are motivated."

In this way, the student selection process sent distinct signals to both incoming and accepted students about expectations and values. While Bragg (1976) also described the structural features of institutions including a "weeding out" process during examinations such as the comprehensive or qualifying examinations, faculty did not mention this as part of their experience. Instead, psychology faculty members talked about the weeding out of undesirable students as those who failed to demonstrate professional competencies during their internships.

Psychology 2 "There were just some issues with her professionalism."

A second element of the institutional and programmatic structure is that of the isolation of students from external influences (Bragg, 1976). By its nature, a full-time doctoral program encompasses a tremendous amount of the student's time and energies. The student spends an inordinate amount of time with faculty and other students in the program, in effect isolating themselves from external influences.

Interdisciplinary 2 "It takes a whole academic community to raise a scholar and to develop a scholar. While social friends and family can support the person by telling them they're smart, motivated, and that they're proud of them, they don't have the academic credibility [with the student]." 
While few other faculty members discussed the importance of isolation from external influences, there was nevertheless an emphasis placed upon the value of time in regard to the student's commitment to the program. Time was expected to be spent in the program and interacting with program individuals, thereby implicitly removing the student from external influence.

Consistency of program goals is the third feature of educational institutions (Bragg, 1976). Faculty in the study explained that their programs' coherency and consistency was often a key strength that facilitated their students' success. Indeed, faculty often remarked upon the small size of their programs as a facilitator of this consistency.

Psychology 1 "We are a small, cohesive faculty. We are unified in our approach to psychology and training; a lot of communication and common goals."

Closely connected was the fourth feature, the explicitness of values and role models (Bragg, 1976). Many of the values the faculty described included those of collegiality and cohesiveness as well as an atmosphere that told students - in the words of an engineering faculty member - that "it is okay to fail." Faculty commented that they role modeled these behaviors in several ways to their students. Several of the engineers described their department's values as acted out in their collegial interactions with students.

Engineering 1 "We treat our students as co-workers."

Engineering 3 "There's no pulling rank or anything like that."

History 1 "There is a collegiality component to this and some departments have it and some departments don't. We've always been a faculty that gets along so you don't have to worry too much about departmental politics in terms of your committee."

Role models were an added dimension of this fourth feature of the educational setting (Bragg, 1976).

Oceanography 1 "I think you need to have a very high level performance and have strong quality faculty if you're going to have a strong, quality Ph.D. program. I think that's true of everything in life: you're not going to be a good hamburger flipper at McDonald's unless you have a good hamburger flipper teaching you."

Psychology 2 "I think you can accomplish so much more by collaborating with other people than you can by yourself. I think we really do model that to the students. We're pretty tightly knit and supportive of one another."

The fifth feature of educational institutions, as described by Bragg (1976), includes the provisions of opportunities for practicing responses. For the majority of the faculty, this played out in their classroom interactions with students as well as those in the research laboratory or dissertation. In history and oceanography at LGU, opportunities to practice responses came in the form of graduate student symposia, whereas in engineering they came from the research laboratory.

History 2 "We also have a symposium in which graduate students participate and present their work formally. I think that helps students a lot to develop the confidence they need to give papers and that kind of thing."

Engineering 4 "You give lessons on how to get to a final solution and they have to find it by themselves. But there is a difference for master's and Ph.D. students: a master's produces new data and a Ph.D. produces new answers. The key to advising is to ask the right questions otherwise it is not teaching them the scientific method."

Bragg (1976) described the last feature of the educational setting as "the provision of both positive and negative sanctions as feedback to students" (p. 14). Again, for most of the faculty, this 
came in the form of feedback in the classroom, often specifically addressed to the students' writing.

History 3 "We have a lot of writing problems when people start. Sometimes you need to tell them not be a perfectionist and other times you need to light their fire a little bit. In both cases, it seems important to encourage them."

Psychology 1 "There's a section of our meeting updating student progress and at the end of every semester we do a thorough review with each student. Those meetings create space for just updating how students are doing and there's a lot of attention toward all aspects of their development."

\section{Interaction among Students in the Program}

While the faculty were able to offer multiple examples of the ways in which their students interact with the educational structure of their doctoral programs, relatively few faculty mentioned the role that the student peer culture plays in the socialization experience. It was only the faculty in history and engineering (and, to a lesser extent, the faculty in psychology) who spoke of the important role of peers in the socialization process. For example, two different engineering faculty talked about the role that cross-generational peer mentoring played for their students.

Engineering 3 "We also have post-docs who are just part of the research team and they get to see how a post-doc functions and they get to know a little bit about that stage."

History 1"I think we try as much as we can as a department to help with the culture of participation among the graduate students. What we've done to foster that culture of participation is basically to create a space for them, a room downstairs, where they can meet and get together."

The psychology program, on the other hand, focused this peer interaction around "a peer proseminar" where students present their research to one another to gain feedback at all parts of the research process.

Interestingly enough, it was the absence of such peer interaction that connected the interdisciplinary faculty members' remarks. In this program, students are able to self-design a doctoral program by bringing together three or more existing disciplinary programs. This program is then, by its nature, independent and therefore without a common student community.

The interdisciplinary Ph.D. (I.Ph.D.) faculty members were cognizant of this lack of peer community and expressed concern about it.

Interdisciplinary 3 "My own program was cohort based, with people behind us and in front of us so we had some kind of coaching, and it worked really well. So I can compare that structure to what the I.Ph.D. is and frankly I don't know I could handle an I.Ph.D."

Interdisciplinary 1 "It is really lonely. My students complain that it's a very lonely process. They do not have a cohort or other doctoral students to go to. It's a painful process for them."

\section{Interaction between Students and Faculty Members}

The final element of Bragg's (1976) framework of socialization relates to the interaction that students have with faculty members. Bragg explained, "The faculty members transmit their attitudes, values, and behavioral norms both formally - through the structures they establish and through the courses they teach - and informally - through individual advising and supervising of study and through social activities" (pp. 19-20). 
Indeed, the faculty members in this study explained that it was often the one-on-one advising relationships with their students that constituted the bulk of their socialization. In engineering, the faculty talked about an "open-door policy" that fostered such student-faculty interaction:

Engineering 2 "It is not uncommon for students to just pop in the various offices to get help and they get expertise and guidance from other faculty. We are all, by and large, like that and open to that."

Engineering 4 "I think the key is discussion between student and professor. There must be open discussion I mean really between almost two friends because it requires a lot of trust on both sides. To talk is very important. You solve all the problems by discussion."

In psychology, the faculty explained that their interactions with students are often diverse in nature, lending themselves to mentoring students in multiple capacities.

Psychology 1 "Another thing with our program is that we have a lot of contact with students in multiple roles. I do clinical supervision, research mentoring, and I'm on committees. It's particularly gratifying to see their development across these things."

Faculty also expressed the more informal ways in which they socialize their students.

Oceanography 3 "I have them over for dinner. If there's somebody coming to town like a colleague then I will have them over for dinner so they can socialize with us and be treated like an adult, like a professional."

Oceanography 2 "The best way to [socialize] students is to have a pool of at least three graduate students who interact fairly closely to you. Sometimes that happens entirely within my lab, and more it happens between my lab - in the hallways, the lunch room, et cetera."

In history, this informal interaction often occurs in social settings.

History 2 "We have parties, which is not unimportant, because, for example, at the job interview there will often be informal kinds of socialization in addition to formal socialization. It is important for people to be prepared to talk about ideas and history in an informal and relaxed way as well as in a very prepared way."

Ultimately, this informal interaction is what one oceanography faculty member expressed as "rubbing shoulders."

Oceanography 1 "It's rubbing shoulders in the broadest sense of the term. It's always been true of primates and that is just how the species works."

\section{Explicit Contributions to Doctoral Student Socialization}

After a more pointed protocol that asked faculty to comment on their teaching and advising practices as well as the departmental climate for the students, one last question was posed to the faculty members: "If you had to summarize the ways that you and the program socialize doctoral students, how would you describe this process?" This question was asked simply out of sheer curiosity, as the researcher wondered how faculty would conceptualize the process of socialization and their explicit contribution to this process. Perhaps not surprisingly, then, the majority of faculty members held no more than a naïve conceptualization of their influence in the socialization process and generally considered this socialization to fall within what Weidman et al. (2001) described as formal socialization, or "experiences designed specifically for accomplishing particular goals" as opposed to informal socialization, or the "relatively unstructured experiences" that occur in the doctoral program (p. 7). 
When asked about their role in the socialization process of their doctoral students, nearly every single faculty member mentioned that they encouraged their students to attend and present at conferences.

Oceanography 2 "I make sure they get out in the professional community and make it off to meetings."

Many faculty also discussed other formal aspects of their role in socialization including preparing their doctoral students for careers after graduation, including allowing them to practice job talks and work on curriculum vitae.

Psychology 2 "There is that professional training that goes on in terms of jobs, in helping students developing a job talk and practicing the talk."

Concomitantly, faculty members discussed other formal mechanisms including attending weekly seminars, internships, and working with external professionals on the dissertation. Only two faculty members discussed other formal socialization roles, such as "teaching them how to do research."

On the other hand, when the interdisciplinary program faculty were asked about their explicit role in the socialization process, all of them remarked that they held no such role in the students' experience. Instead, all four of the faculty members felt that this socialization should be happening in the student's career, which is the case for many of their part-time students who work full-time in existing careers.

Interdisciplinary 3 "I don't think I have a big role in that (socialization). I think it's up to the student. It works best if they are already involved in a career and moving forward."

\section{Discussion}

Taken together, what these faculty members described as the socialization process for their doctoral students included several of the core aspects of socialization as discussed by Bragg (1976) and Weidman et al. (2001). For instance, all the faculty members interviewed discussed at length the structure of the educational setting in relation to its effect on doctoral student socialization in their programs. These structures included cohesive goals among faculty in regard to their curricular and programmatic outcomes as well as formal feedback loops to students. In addition, the faculty members were quick to point out the formal and informal aspects of their interaction with students. This includes student access to faculty members, in both formal and informal settings, as well as modeling of collegiality among the different faculty. While relatively fewer faculty discussed the importance of the interaction among students, it was nevertheless a key part of the discussions with faculty in history, oceanography, and, to a lesser extent, in psychology, where they discussed "creating space" for student interaction in offices, lounges, and in programsupported symposia.

At the same time, the interviews with the faculty members point to some discrepant findings among and within the different doctoral programs. For example, a clear cause of concern was discussed by the faculty in the I.Ph.D. program. While this program exists to allow students to create an individualized degree experience, it evidently also allows for a much more loosely coupled experience for the student. Without a group of student peers with whom to interact and without a programmatic structure to provide coherent curriculum, support, and cohesion, the absence of these two major elements of Bragg's (1976) framework is disconcerting. Therefore, even though I.Ph.D. students may develop a relationship and interact with their advisor of choice, students are lacking a larger intellectual community within which to interact and learn. Bragg elucidated the importance of this community when she said, "The level of collegiality perceived by the students is a predictor of both academic and nonacademic satisfaction in graduate school...satisfaction 
does influence both continuation in the program and achievement" (p. 24). Beyond the programmatic structure, the lack of socialization experiences for these I.Ph.D. students is perhaps the function of a largely part-time and older student base. Nevertheless, Weidman et al. (2001) emphasized the importance of cohorts for part-time students, with studies finding that even part-time students will gain "emotional and professional support [that is] important for students' success beyond the university department" from these cohort structures (p. 82). Therefore, the completion rate of this program $(62.0 \%)$ may point more to a dependence on relationships between students and advisors or to the resiliency of the individual student who enters this program.

Regardless of program, it was also interesting to note that the faculty interviewed spoke more often and spoke with more detail about programmatic elements as opposed to more interpersonal and developmental elements in their programs. For example, it was striking how undervalued the role of student peers was for many the faculty. And, even while some faculty members in history, oceanography, and psychology discussed the important role of student community in their programs, it was often a point only shared by one faculty in a particular program. The role of the student community, even while discussed by Bragg (1976) many years ago, has only recently begun to play a larger role in the literature on the doctoral student experience (e.g., Grant-Vallone \& Ensher, 2000; Sweitzer, 2009). This lack of discussion surrounding interpersonal elements of their programs by the faculty could perhaps be explained by faculty spending much more time discussing program requirements and structure than they generally spend speaking about relationships with students, but it also may indicate the underestimated importance these elements play in the socialization experience of students. Weidman et al. (2001) commented, "More collaborative, holistic approaches to learning necessitate systemic change that challenges most existing approaches to graduate and professional study" (p. 93).

When then asked explicitly about their role in socialization, the majority of faculty members interviewed spoke specifically to the involvement aspect of the socialization process or what Weidman et al. (2001) referred to as "the participation in some aspect of the professional role or in preparation for it." (p. 18). In this way, the formal socialization mechanisms discussed by the faculty - such as job search panels and conference presentations - truly were those related to professionalizing their doctoral students for employment after graduate school. As Golde (1998) stated, however, socialization at the doctoral level occurs on two levels: that for the profession after graduate school but also for graduate school itself. It was interesting to note, then, that only a few faculty members talked about knowledge acquisition and the socialization needed to be successful in doctoral education while none discussed the investment aspect of the socialization process.

Informal socialization was therefore discussed much less often by the faculty members interviewed. However, it was interesting to note that it was those faculty members in the sciences who almost exclusively discussed these more informal aspects. This differentiation might be attributed to the full-time and laboratory-based experiences of their doctoral students, in that science faculty members have a much more constant, one-on-one relationship with their doctoral students (Walker, Golde, Jones, Conklin Bueschel, \& Hutchings, 2008). On the other hand, the psychology doctoral students at this institution are also full-time and work closely in labs with their faculty, but their faculty members seemed to be more interested in the formal aspects of career preparation for their students. The interdisciplinary faculty members, who work primarily with part-time students employed in full-time professional roles, did not feel they had time to socialize their students adequately but instead expected the students' "jobs to do that."

Viewing the findings as a whole, then, it was clear that the majority of these faculty members generally did not see the day-to-day interactions they had with their students as those that would contribute to overall socialization, even though the existing literature points to the importance of these interactions (e.g., Boyle \& Boice, 1998; Bragg, 1976; Katz, 1976; Pease, 1967; Weidman et 
al., 2001). It is apparent that the majority of faculty interviewed at this institution do not see the important roles they play in their doctoral students' socialization and, more often than not, attributed the socialization their students receive to external agents and experiences - as occurring, for example, in national conferences or with guests invited to speak at weekly seminars.

\section{Implications}

Several implications for policy, practice, and future research emerge from the findings of this study. Foremost, given the importance of successful socialization in doctoral education and its role in doctoral student completion (Council of Graduate Schools, 2004), institutions and their faculty should be more cognizant of their roles as well as the roles of peers and the educational structure in the socialization process (Bragg, 1976). This can begin through more purposeful discussions among faculty and program administrators about the socialization process in the respective doctoral program, or even across doctoral programs as instituted by an institution's graduate school dean or administrator. Such discussions can begin with conversations about the intended outcomes of the doctoral program in terms of student skills, attitudes, and habits of mind (see Gardner, Hayes, \& Neider, 2007), followed by conversations that consider programmatic, personal, and interpersonal experiences to facilitate the development of these skills, attitudes, and habits of mind. In total, more purposeful discussions of facilitating learning and development are vital to creating an environment of student success (Weidman et al., 2001).

Students should also be integral parts of these discussions. For example, a survey of program alumni or even employers may result in learning more about what graduates believe would have better prepared them for their current professional environment. Surveying current students and involving these students in program-wide and university-wide discussions of socialization will also be helpful in this regard. Program faculty should also encourage the formal development of doctoral student associations and organizations to facilitate more student interaction as well as to create space in which students can congregate and interact. Peer mentoring programs can also be developed to assist students in creating relationships with their peers from the beginning of the program and continuing throughout. Self-designed interdisciplinary doctoral programs, such as the one featured in this study, should also be structured to facilitate more student interaction as well as more program cohesion. This might be facilitated by a required course in interdisciplinarity for all entering students, a peer mentoring program, and through more structured guidelines for degree completion by the graduate school that oversees the program.

While contributing to the sparse literature on this topic, the current study was nevertheless limited in terms of both disciplinary and institutional parameters. Future studies should therefore include different combinations of disciplines and institutions but also could compare disciplinary perspectives within different institutions. For example, how does institutional context (size, location, ranking, resources, etc.) factor into how faculty in a particular discipline view the socialization experience? Similarly, how does the student population (part-time vs. full-time, younger vs. older, etc.) within a particular program influence perspectives of the socialization process? In this way, comparisons of faculty views of the socialization process combined with their students' perspectives would also be informative. Finally, future studies could also explore how different demographic variables influence faculty views on socialization, such as race, gender, sexual orientation, as well as student perceptions post-graduation.

\section{Conclusion}

The purpose of this study was to better understand faculty perceptions of doctoral student socialization across disciplines. The findings from this study contributed to this under-examined area of the literature as well as provided implications for those who work with and structure graduate programs for doctoral students. Specifically, faculty members' contributions to the socialization 
of students go beyond the explicit expectations as determined in the faculty role, including teaching, advising, and career preparation, to the more implicit expectations of their behaviors, mannerisms, and attitudes. A more comprehensive awareness of their impact upon students might therefore be a part of faculty professional development programs and literature. Moreover, while the literature on doctoral education speaks extensively to the important role of faculty in the socialization of doctoral students, rarely are faculty asked about this role. Engaging faculty in these conversations within doctoral programs may go a long way in better structuring opportunities for doctoral student socialization and activities and structures that may facilitate it. Taken together, through an awareness of both the formal and informal opportunities for socialization, faculty can assist their students in preparing them to be both successful students and successful future professionals.

\section{References}

Aguinis, H., Nesler, M. S., Quigley, B. M., Suk-Jae, L., \& Tedeschi, J. T. (1996). Power bases of faculty supervisors and educational outcomes for graduate students. The Journal of Higher Education, 67, 267-297.

Aldersley, S. F. (1995). 'Upward drift' is alive and well. Change, 27(5), 50-56.

Antony, J. S. (2002). Reexamining doctoral student socialization and professional development: Moving beyond the congruence and assimilation orientation. Higher education: Handbook of theory and research (Vol. XVII, pp. 349-380). New York, NY: Agathon Press.

Austin, A. E. (2002). Preparing the next generation of faculty: Graduate school as socialization to the academic career. The Journal of Higher Education, 73, 94-121.

Baird, L. L. (1992). The stages of the doctoral career: Socialization and its consequences. Paper presented at the American Educational Research Association, San Francisco, CA.

Baird, L. L. (1995). Helping graduate students: A graduate adviser's view. In A. S. Pruitt-Logan \& P. D. Isaac (Eds.), Student services for the changing graduate student population (pp. 25-32). San Francisco, CA: Jossey-Bass.

Bargar, R. R., \& Mayo-Chamberlain, J. (1983). Advisor and advisee issues in doctoral education. The Journal of Higher Education, 54, 407-432.

Barnes, B. J., \& Austin, A. E. (2009). The role of doctoral advisors: A look at advising from the advisor's perspective. Innovative Higher Education, 33, 297-315.

Bess, J. L. (1978). Anticipatory socialization of graduate students. Research in Higher Education, 8, 289317.

Bess, J. L., \& Dee, J. R. (2008). Understanding college and university organization: Theories for effective policy and practice. Sterling, VA: Stylus.

Biglan, A. (1973). The characteristics of subject matter in different academic areas. Journal of Applied Psychology, 57, 195-203.

Bogdan, R. C., \& Biklen, S. K. (2003). Qualitative research for education: An introduction to theories and methods. Boston, MA: Allyn and Bacon.

Boyle, P., \& Boice, B. (1998). Best practices for enculturation: Collegiality, mentoring, and structure. In M. S. Anderson (Ed.), The experience of being in graduate school: An exploration (pp. 87-94). San Francisco, CA: Jossey-Bass.

Bragg, A. K. (1976). The socialization process in higher education. Washington, DC: The George Washington University.

The Carnegie Foundation. (2010). The Carnegie classification of institutions of higher education. Retrieved February 16, 2010, from http://classifications.carnegiefoundation.org/index.php 
Clark, S. M., \& Corcoran, M. (1986). Perspectives on the professional socialization of women faculty: A case of accumulative disadvantage? The Journal of Higher Education, 57, 20-43.

Council of Graduate Schools. (2004). Ph.D. completion and attrition: Policy, numbers, leadership, and next steps. Washington, DC: Author.

Council of Graduate Schools (2008). Ph.D. completion and attrition: Analysis of baseline program data from the Ph.D. completion project. Washington, DC: Author.

Ellis, E. M. (2001). The impact of race and gender on graduate school socialization, satisfaction with doctoral study, and commitment to degree completion. The Western Journal of Black Studies, 25, 3045.

Frentz, K. T. (1991). Comparison of graduate student socialization in two selected disciplines. Unpublished doctoral dissertation, Florida State University.

Gardner, S. K. (2007). "I heard it through the grapevine": Doctoral student socialization in chemistry and history. Higher Education, 54, 723-740.

Gardner, S. K. (2009). Conceptualizing success in doctoral education: Perspectives of faculty in seven disciplines. Review of Higher Education, 32, 383-406.

Gardner, S. K., Hayes, M. T., \& Neider, X. (2007). The dispositions and skills of a Ph.D. in education: Perspectives of faculty and graduate students in one college of education. Innovative Higher Education, 31, 287-299.

Golde, C. M. (1998). Beginning graduate school: Explaining first-year doctoral attrition. In M. S. Anderson (Ed.), The experience of being in graduate school: An exploration (pp. 55-64). San Francisco, CA: Jossey-Bass.

Golde, C. M. (2005). The role of the department and discipline in doctoral student attrition: Lessons from four departments. Journal of Higher Education, 76, 669-700.

Gonzalez, J. C. (2006). Academic socialization experiences of Latina doctoral students: A qualitative understanding of support systems that aid and challenges that hinder the process. Journal of Hispanic Higher Education, 5, 347-365.

Grant-Vallone, E. J., \& Ensher, E. A. (2000). Effects of peer mentoring on types of mentor support, program satisfaction and graduate student stress: A dyadic perspective. Journal of College Student Development, 41, 637-642.

Heinrich, K. T. (1995). Doctoral advisement relationships between women: On friendship and betrayal. The Journal of Higher Education, 66, 447-469.

Holley, K. (2006). The cultural construction of interdisciplinarity: Doctoral student socialization in an interdisciplinary neuroscience program. University of Southern California, Los Angeles.

Isaac, P. D., Quinlan, S. V., \& Walker, M. M. (1992). Faculty perceptions of the doctoral dissertation. The Journal of Higher Education, 63, 241-268.

Katz, J. (1976). Development of the mind. In J. Katz \& R. T. Hartnett (Eds.), Scholars in the making: The development of graduate and professional students (pp. 107-126). Cambridge, MA: Ballinger.

Keith, B., \& Moore, H. A. (1995). Training sociologists: An assessment of professional socialization and the emergence of career aspirations. Teaching Sociology, 23, 199-214.

Kuh, G. D., \& Whitt, E. J. (1988). The invisible tapestry: Culture in American colleges and universities. Washington, DC: The George Washington University.

LeVine, R. A. (1966). American college experience as socialization process. In T. M. Newcomb \& E. K. Wilson (Eds.), College peer groups: Problems and prospects for research (pp. 107-132). Chicago, IL: Aldine. 
Margolis, E., \& Romero, M. (1998). "The department is very male, very white, very old, and very conservative": The functioning of the hidden curriculum in graduate sociology departments. Harvard Educational Review, 68, 1-32.

Maxwell, J. A. (1996). Qualitative research design: An interactive approach. Thousand Oaks, CA: Sage.

Mendoza, P. (2007). Academic capitalism and doctoral student socialization: A case study. Journal of Higher Education, 78, 71-96.

Merton, R. K. (1957). Social theory and social structure. New York, NY: The Free Press.

Pease, J. (1967). Faculty influence and professional participation of doctoral students. Sociological Inquiry, 37, 63-70.

Rosen, B. C., \& Bates, A. P. (1967). The structure of socialization in graduate school. Sociological Inquiry, $37,71-84$.

Samuel, R. E., \& Kohun, F. G. (2010). Managing perceived coping behavior while mentoring doctoral students. International Journal of Doctoral Studies, 5, 29-37. Retrieved from http://ijds.org/Volume5/IJDSv5p029-037Samue291.pdf

Schroeder, D. S., \& Mynatt, C. R. (1993). Female graduate students' perceptions of their interactions with male and female major professors. The Journal of Higher Education, 64, 555-573.

Sorenson, G., \& Kagan, D. (1967). Conflicts between doctoral candidates and their sponsors: A contrast in expectations. The Journal of Higher Education, 38, 17-24.

Sweitzer, V. (2009). Towards a theory of doctoral student professional identity development: A developmental networks approach. The Journal of Higher Education, 80, 1-33.

Tierney, W. G. (1997). Organizational socialization in higher education. The Journal of Higher Education, $68,1-16$.

Turner, C. S. V., \& Thompson, J. R. (1993). Socializing women doctoral students: Minority and majority experiences. The Review of Higher Education, 16, 355-370.

Van Maanen, J. (1984). Doing new things in old ways: The chains of socialization. In J. L. Bess (Ed.), College and university organization: Insights from the behavioral sciences (pp. 211-247). New York, NY: New York University Press.

Walker, G. E., Golde, C. M., Jones, L., Conklin Bueschel, A., \& Hutchings, P. (2008). The formation of scholars: Rethinking doctoral education for the twenty-first century. San Francisco, CA: Jossey-Bass.

Weidman, J. C., \& Stein, E. L. (2003). Socialization of doctoral students to academic norms. Research in Higher Education, 44, 641-656.

Weidman, J. C., Twale, D. J., \& Stein, E. L. (2001). Socialization of graduate and professional students in higher education: A perilous passage? San Francisco, CA: Jossey-Bass.

Zhao, C.-M., Golde, C. M., \& McCormick, A. C. (2007). More than a signature: How advisor choice and advisor behaviour affect doctoral student satisfaction. Journal of Further and Higher Education, 31, 263-281. 


\section{Biography}

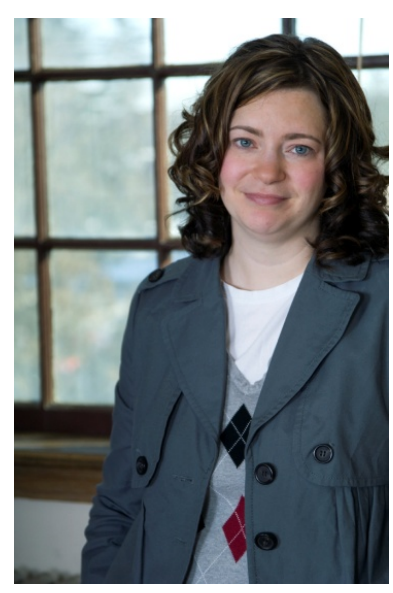

Susan K. Gardner, Ph.D., is associate professor of Higher Education at the University of Maine in Orono, ME, USA. Her scholarly interests focus on the socialization and success of doctoral students as well as the experiences of underrepresented populations in higher education environments. Questions and comments can be directed to susan.k.gardner@maine.edu. 